\title{
Effects of Mesenchymal Stem Cells and Their Derived Microvesicles on Pulmonary Toxicity Induced by Petrol Exhaust Nanoparticle; Histological and Immuno-Histochemical Study
}

\author{
Sherifa Abd El Salam ${ }^{1 *}$, Eman Mohamed Faruk ${ }^{1}$, Hanan Fouad ${ }^{2}$ \\ and Naglaa Yehia Nafie ${ }^{3}$ \\ ${ }^{1}$ Departments of Histology and Cytology, Benha University, Egypt. \\ ${ }^{2}$ Department of Medical Biochemistry, Faculty of Medicine, Cairo University, P.O.Box 115622, Egypt. \\ ${ }^{3}$ Departments of Physiology, Faculty of Medicine, Benha University, Egypt.
}

Authors' contributions

This work was carried out in collaboration among all authors. All authors read and approved the final manuscript.

Article Information

DOI: 10.9734/ARRB/2019/v31i630070

Editor(s):

(1) Dr. Paola Angelini, Department of Applied Biology, University of Perugia, Perugia, Italy. (2) Dr. George Perry, Dean and Professor of Biology, University of Texas at San Antonio, USA.

Reviewers:

(1) Lourens JC Erasmus, University of Limpopo, South Africa.

(2) Nursel Gül, Ankara University, Turkey. Complete Peer review History: http://www.sdiarticle3.com/review-history/49401

Original Research Article

Received 14 March 2019

Accepted 29 May 2019

Published 04 June 2019

\section{ABSTRACT}

Background: Diesel vehicles exhaust contains toxic nanoparticles that drastically affect lung tissue due to their direct cytotoxic effects, induction of oxidative stress, inflammatory signaling pathways and DNA damage. Mesenchymal stem cells (MSCs) exhibit anti-inflammatory effects and efficient regenerative capacity in chronic lung diseases.

Objectives: Evaluation of the effects of MSCs and MSCs-derived micro vesicles (MSCs-MVs) on pulmonary toxicity induced by diesel exhaust nanoparticles (DENPs).

Materials and Methods: Sixty male rats were equally divided into: Group I (Control rats), Group II (DENPs group) received repeated doses of DENPs $(180 \mu \mathrm{g} / \mathrm{rat})$ intratracheally every other day for 6 days, Group III (MSCs group) received MSCs intravenously $\left(3 \times 10^{6}\right.$ cells) after the last dose of 
DENPs and Group IV (MSCs-MVs group) received MSCs-MVs $(0.5 \mathrm{mg} / \mathrm{mL})$ intravenously after the last dose of DENPs. Lung tissue were subjected to histological and immunohistochemical assessment. Inflammatory cytokines and bronchoalveolar lavage fluid (BALF) contents of inflammatory cells, albumin, LDH and total proteins were evaluated.

Results: Histological picture of lung tissue in DENPs group showed numerous collapsed alveoli, thick interalveolar septa and marked cellular infiltration. Elastic fibers were markedly decreased by DENPs. Increased optical density of NF-kB/p65 immunoreactivity. Bronchoalveolar lavage fluid showed significant elevation of inflammatory cytokines (TNF-a, IL-6), polymorphonuclear leukocytes (PMN), neutrophils, macrophages, LDH, total proteins and albumin. Treatment with either MSCs or MSCs-MVs led to a significant amelioration of all of the aforementioned studied parameters.

Conclusion: MSCs-MVs and MSCs showed significant therapeutic effects against DENPs damaging effects on the lung tissues via their regenerative capacity and anti-inflammatory effects.

Keywords: Diesel exhaust nanoparticles; MSCs; pulmonary toxicity; microvesicles.

\section{INTRODUCTION}

Diesel engine exhaust nanoparticles (DENPs) were classified by the World Health Organization as a group 1 carcinogen to humans [1]. Epidemiological data showed that exposure to DENPs is associated with higher risk of morbidity and mortality related to pulmonary and cardiovascular diseases, development and progression of atherosclerosis and lung cancer [2]. The Lung is the first target confronted by DENPs-mediated damage. The most prominent cellular responses are the induction of pulmonary oxidative stress and pro-inflammatory signaling cascade which are known to contribute to the onset of chronic respiratory diseases such as chronic obstructive pulmonary disease (COPD) and lung fibrosis. Fibrotic respiratory disorders develop as consequences of DENPs-induced oxidative stress, chronic inflammation, bronchial asthma and genotoxicity $[3,4]$.

Up to our best of knowledge there are no previous studies conducted on the use of stem cells in DENPs mediated pulmonary toxicity. However, Mesenchymal stem cells (MSCs) showed prominent anti-inflammatory and antioxidant effects in other chronic diseases such as rheumatoid arthritis [5], atherosclerosis [6], inflammatory bowel diseases [7] and inflammatory skin diseases [8]. MSCs mediate significant immunomodulatory effects by modulation of $T$ and $B$ cell proliferation and differentiation, dendritic cell growth and the activity of natural killer cells [9]. MSCs are polarized towards the anti-inflammatory directions in several auto-immune disorders with down-regulation of pro-inflammatory cytokines [5].

Stem cells are endowed with major capacity of multilineage differentiation and self-renewal which allows them to be a significant contributor in tissue homeostasis. Moreover, stem cells have an efficient DNA repair machinery that protects them and the surrounding niche from genotoxic insults [10-12]. Diesel exhaust nanoparticles exhibit marked genotoxic potentials by their direct oxidative DNA damage with single strand breaks, and down-regulation of expression of genes involved in DNA damage repair [13]. Stem cells have the potentials to efficiently combat the genotoxicity induced by DENPs.

Cells release Extracellular vehicles (EVs), as microvesicles, apoptotic bodies and exosomes [14]. They are differentiated by specific membrane markers and size [microvesicles $(100-1000 \mathrm{~nm})$, exosomes $(50-150 \mathrm{~nm})$ and apoptotic bodies (50-2000 nm)]. EVs have been seen in blood, bile, urine bronchoalveolar lavage fluids (BALF), feces and saliva $[15,16]$.

This study aimed at evaluation of the effectiveness of MSCS-MVs and MSCs against pulmonary toxicity induced by DENPs.

\section{MATERIALS AND METHODS}

\subsection{Animals and Groups}

Sixty male rats; albino species (80-120 days old and $220-250 \mathrm{~g} \mathrm{B.Wt}$ ) were obtained from the animal house of faculty of Veterinary Medicine, Benha University. Seven days acclimatization period was allowed for rats. Animals were housed at constant temperature $\left(22 \pm 2^{\circ} \mathrm{C}\right)$ and humidity $(60 \%)$, with a $12: 12$ hour light: dark cycle. They were given water ad libitum and standard pellet diet. All animals' procedures were performed in accordance with the recommendations for the proper care and use of 
laboratory animals. Institutional animal ethical committee reviewed \& approved our study according to the standard protocols of the Institutional Animal Care Committee.

Animals were randomly divided into the following groups:

Group I (Control group, $\mathrm{n}=15$ ) divided into:

Subgroup 1A $(n=8)$. Animals received intravenous injection of phosphate buffered saline (PBS) for 4 weeks.

Subgroup 1B $(n=7)$ : Received normal saline with $0.01 \%$ tween 80 as spray for 6 days intratracheally every two days.

Group II (DENPs group, $n=15$ ).

Animals treated with repeated doses of DENPs $180 \mu \mathrm{g} / \mathrm{rat}$ for 6 days intratracheally every two day.

Group III (MSCs group, n=15).

Rats received a single dose of $3 \times 10^{6}$ MSCs intravenously suspended in 0.5 $\mathrm{mL}$ PBS after the last dose of DENPs ( DENPs $180 \mu \mathrm{g} /$ rat for 6 days intratracheally every two day) .

Group IV (MSCs-MVs group, $\mathrm{n}=15$ )

Rats treated intravenously with a single dose of $0.5 \mathrm{~mL}(0.5 \mathrm{mg} / \mathrm{mL})$ of MSCsMVs after the last dose of DENPs ( DENPs $180 \mu \mathrm{g} /$ rat for 6 days intratracheally every two day) .

In DENPs exposed rat groups, sodium pentobarbital was injected for anesthesia intraperitoneally $(60 \mathrm{mg} / \mathrm{kg}$ b.wt). A 24gauge cannula via the mouth was inserted into the trachea. The DENPs suspensions and normal saline were intratracheally instilled using a sterile syringe. Administration was done on days 1,3 , and 5 .

\subsection{Collection of DENPs}

DEHP, di(2-ethylhexyl) phthalate, (CAS no 204$211-0$, purity $99 \%$, lot $101 \mathrm{~K} 3696$ ) was purchased from Sigma Aldrich (St Louis, MO) dissolved in $0.5 \%$ DMSO (Sigma-Aldrich ${ }^{\circledR}$, St Louis, MO) for $6,12,24$ or $48 \mathrm{~h}$. Collection of DENPs were done by operating petrol engines and duty light multicylinder diesel at a speed of $1500 \mathrm{rpm}$, as method mentioned by Durga et al. [17]. They were suspended in sterile normal saline ( $\mathrm{Nacl}$ $0.9 \%)$ containing tween $80(0.01 \%)$ to decrease aggregation, Normal saline with $0.01 \%$ tween 80 was given to control group (tween is a non-ionic detergent used as an emulsifying agent in biochemical applications-Cat No.9005-64-5). The size of collected particles was less than $2.5 \mu \mathrm{m}$. Morphological analysis and demonstration of the presence of nano-size particles were examined by Transmission Electron Microscope (HR-TEM) (JEOL 3010).

\subsection{MSCs Isolation and Ex Vivo Expansion}

At the end of the experiment, the rats were sacrificed by cervical dislocation. Bone marrow cells were obtained by flushing femurs and tibias with sterile PBS. After centrifugation, cells were resuspended in alpha-MEM supplemented with $10 \%$ selected fetal bovine serum and $80 \mathrm{ug} / \mathrm{mL}$ gentamicin and plated at a density of $1 \times 10^{6}$ nucleated cells $/ \mathrm{cm}^{2}$. Non-adherent cells were removed after 72 hours by media change. When foci reached confluence, adherent cells were detached with $0.25 \%$ trypsin, $2.65 \mathrm{mM}$ EDTA, centrifuged and subcultured at $7.000 \mathrm{cells} / \mathrm{cm}^{2}$. After two subcultures, adherent cells were characterized and transplanted [18].

\subsection{Immunophenotyping of MSCs}

Immunophenotyping was performed by flowcytometric analysis after immunostaining with monoclonal antibodies against CD73 (FITCconjugated) from BD Pharmingen, USA, and CD90 (PE-conjugated), (HPA005785 SigmaAldrich, St. Louis, MO, USA) [18].

\subsection{MSCs Intravenous Administration}

A total of $0.5 \times 10^{6} \mathrm{MSC}$ were suspended in 0.2 $\mathrm{mL}$ of $5 \%$ BPS and were administered via the tail vein rat. Control animals received $0.2 \mathrm{~mL}$ of vehicle.

\subsection{Isolation of MSC-derived Microvesicles}

Microvesicles were isolated from supernatant of first, second, and third passages of MSCs cultured in a-MEM deprived of FBS [AQ10]. After centrifugation at $2000 \mathrm{xg}$ for $20 \mathrm{~min}$ to remove 
debris, cell-free supernatant was centrifuged at $100,000 \mathrm{xg}$ (ultracentrifuge of Beckman Coulter Optima L $90 \mathrm{~K}[\mathrm{AQ} 11])$ for $1 \mathrm{~h}$ at $4^{\circ} \mathrm{C}$, washed in serum-free medium 199 containing HEPES 25 $\mathrm{mM}$ (Cat. No. 5000205, Sigma, St Louis, Missouri, USA), and subjected in the same conditions to a second ultracentrifugation [19].

\subsection{Identification and Detection of MSC- derived Microvesicles}

Flow cytometry was done for identification of MSCs using specific stem cell markers CD90 (SAB4700594-100UG, Becton Dickinson, FACS Calibur) and CD44 (SAB1402714100UG, Miltenyi Biotec, Bergisch Gladbach, German) [20] and detection of MSCs-MVs was done by using transmission electron microscope (JEM-2100, Joel Inc.) at $80 \mathrm{kV}$ ) [21]. For detection of homing of MSCs into pulmonary tissue in rats, cells were labeled with PKH26 Red Fluorescent Cell Linker Kit (PKH26GL, SigmaAldrich, Egypt) then were injected into the tail vein, the lung tissue was examined with a fluorescence microscope to detect the cells stained with $\mathrm{PKH} 26$ dye to ensure homing in tissue.

\subsection{Histological Studies}

At the end of the experiment, animals were anaesthetized by ether inhalation, sacrificed and the lung was exposed and excised. Lung biopsies were divided and fixed immediately in $10 \%$ neutral buffered formalin. Paraffin sections were prepared and stained with hematoxylin and eosin (H \&E) to verify histological details, Orcein stain was used to assess elastic fibers [22].

Immunohistochemical staining was carried for the detection of expression of NF--KB (Labvision, Thermoscientific, USA) rabbit polyclonal antibody, CA. RB-1638.

Immunohistochemical staining was done by using avidin-Biotin immunoperoxidase technique in which lung sections from paraffin block were cut. Peroxidase Blocking Solution was used to block the endogenous peroxidase for $15 \mathrm{~min}$, the slides were put in citrate buffer for antigen retrieval, then put in the microwave for $9 \mathrm{~min}$ at $90^{\circ} \mathrm{C}$ and the slides were incubated at room temperature after cooling with the diluted primary antibodies (1:50). Finally, Diaminobenzidine (DAB) chromogen solution was added and counter staining was done with Mayer's hematoxylin. For negative control sections, the primary antibodies were excluded. The reaction is cytoplasmic and the positive control was taken from the prostate [23].

\subsection{Morphometric Study}

Measurement of alveolar wall thickness was done in H\&E stained sectioned, measurement of mean area\% of elastic fiber content was measured in the Orcien-stained sections at a magnification of $\times 400$ for each specimen and measurement of the optical density of NF-KB immunoreactivity was done in 10 high-power fields using the binary mode. All above measurements were quantified in 10 images for each group using Image-Pro Plus program version 6.0 (Media Cybernetics Inc., Bethesda, Maryland, USA). (Computer system in the morphometric unit in the Histology Department, Faculty of Medicine, Cairo University).

\subsection{Collection and Analysis of Bronchoalveolar Lavage Fluid (BALF)}

After scarification of all animals the trachea was canalized and the lungs were washed 3 times with $7.0 \mathrm{ml}$ of normal sterile saline ( $\mathrm{Nacl} 0.9 \%$ ). There were no differences in volume of BALF collected from different groups. The collected BAL fluid was centrifuged for $15 \mathrm{~min}$ at $1500 \mathrm{rpm}$ to precipitate the cells. The cells were then washed with buffer consisting of $0.58 \mathrm{~g}$ $\mathrm{Na} 2 \mathrm{HPO} 4,4.03 \mathrm{~g} \mathrm{NaCl}, 0.1 \mathrm{~g} \mathrm{KCl}, 0.5 \mathrm{~g}$ glucose and $0.1 \mathrm{~g} \mathrm{KH} 2 \mathrm{PO} 4$ in $500 \mathrm{ml}$ of distilled water and finally suspended at $2 \times 10^{5}$ cells $/ \mathrm{ml}$ in buffer. This was followed by staining with diff-quick (Belgium), fixation in methanol and observation under a light microscope. The concentration of macrophages, polymorphonuclear leukocytes (PMN), neutrophil, total cell count and total protein in BALF was analyzed according to the described protocols [24]. Total protein and albumin were assayed as an indicator of elevated permeability of capillary-bronchoalveolar barrier [25]and lactate dehydrogenase $(\mathrm{LDH})$ estimation was assessed as an indicator of lung tissue injury [26]. Cytokines analysis of Interleukin-6 (IL-6) and tumor necrosis factor (TNF- $\alpha$ ) was also done in BALF. Total protein of BAL fluid was quantified by Bradford reagent (BioRad, Hercules, $\mathrm{Ca}$ ) as directed by the manufacturer's protocol. Lactate dehydrogenase $(\mathrm{LDH})$ was assayed using colorimetric assay kit (Sigma-Aldrich, Merck, USA. Cat No. MAK066). Albumin (BCG) assay kit was obtained from Abcam (UK, Cat No. ab235628). ELISA kits were 
used for IL- 6 and TNF alpha assays (Abcam, UK, Cat No. ab100772 \& Cat No. ab100785 respectively). All assays were conducted as directed by the manufacturer's protocols.

\subsection{Statistical Analysis}

Data was analyzed using SPSS computer program version 22.0. Quantitative data was expressed as means \pm standard deviation, median and range. Qualitative data was expressed as number and percentage. The data were tested for normality using Shapiro-Wilk test. The nonparametric Mann-Whitney test and Kruskal-Wallis test were used for data which wasn't normally distributed. Independent Samples t-test and One-way analysis of variance test were used for normally distributed data. ChiSquare test was used for comparison between qualitative variables. A $5 \%$ level was chosen as a level of significance in all statistical tests used in the study.

\section{RESULTS}

\subsection{Histological Results}

\subsubsection{Characterization and homing of MSCs and MSCs-MVs}

MSCs were recognized at 14-day culture by inverted microscope as adherent spindle-shaped cells with some polyhedral cells in between (Fig. 1A). MSCs labelled with PKH26 fluorescent dye were identified in vitro by means of a fluorescent microscope (Fig. 1B). MSCs labelled with PKH26 fluorescent dye were recognized in lung by their strong red fluorescence using fluorescent microscope (Fig. 1C). TEM of MSCs-MVs showed spheroids appearance with diameter less than $100 \mathrm{~nm}$ (Fig. 1D). Flow cytometry revealed that there were positive CD90 and CD44 as surface marker of MSCs.

\subsubsection{Hematoxylin and eosin results (H\&E)}

Examination of lung sections of control rats (group I) showed a normal lung structure with bronchioles and blood vessels in between lung alveoli that has thin inter alveolar septa (Fig. $2 \mathrm{~A}$, 2B). The lung alveoli of group II (DENPs treated group) showed thick interalveolar septa with inflammatory cellular infiltration around alveoli and bronchiole, extravasated red blood cells (RBCs) and desquamated epithelial cells in the lumen of the bronchiole (Fig. 2C, 2D) In group III (MSCs treated) lung sections revealed bronchioles, alveoli with thin interalveolar septa.
Few cellular infiltrations and less extravasated RBCs were detected (Fig. 2E, 2F). Lung sections in group IV (MSCs-MVs) showed many alveoli of variable size with alveolar ducts and thin interalveolar septa as in control group while few others showed thickened interalveolar septa with few mononuclear cellular infiltration (Fig. 2G).

\subsubsection{Orcein stain results}

Group I sections showed continuous dark reddish-brown elastic fibers around the bronchiole, walls of the alveoli and wall of blood vessels (Fig. 3A). Sections of group II showed minimal accumulation of reddish-brown elastic fibers around the bronchiole, walls of the alveoli, and wall of dilated congested blood vessel (Fig. 3B). Group III (MSCs group) lung tissue showed moderate accumulation of reddish-brown elastic fibers around the bronchiole, wall of congested blood vessel, and walls of the alveoli (Fig. 3C). Group IV (MSCs-MVs) lung showed marked accumulation of reddish-brown elastic fibers in the bronchiole, wall of congested blood vessel and walls of the alveoli (Fig. 3D).

\subsubsection{Immunohistochemical results}

The NF-KB immunoreactivity in the control groups was showed cytoplasmic immunoreactivity in some alveoli (Fig 4A). In the DENPs group, increased cytoplasmic immunoreactivity was observed in multiple alveolar cells (Fig. 4B), whereas the (MSCs group) and (MCSs-MVS group) showed decreased cytoplasmic immunoreactivity in alveoli compared with the DENPs group (Figs. $4 C$ and $D$ ).

\subsection{Morphometric Results}

\subsubsection{The alveolar septal wall thickness}

Group II (DENPs group) showed significant increase in the alveolar thickness $(p<0.001)$ in comparison to control. While the alveolar thickness in Group III (MSCs group) and in Group IV (MSCs-MVs group) exhibited significant decrease $(p<0.05)$ (Table 1$)$.

\subsubsection{Mean area percentage of elastic fibers}

There was a significant difference in the mean area percentages of elastic fibers in DENPs group as compared with control group $(p>0.05)$ and a significant increase in elastic fibers in both MSCs and MSCs-MVs treated groups in comparison to DENPs group $(p<0.05)$ (Table 1$)$. 


\subsubsection{Optical density of NF-KB}

There was a significant increase $(P<0.05)$ in the mean optical density of NF-kB immunoreactivity in the DENPs group compared with the other groups (Table 1).

\subsubsection{Cytokine analysis, inflammatory cells and total proteins in BALF}

In Group II (DENPs group), the levels of TNFa and IL-6 were significantly increased in BALF.
However, IL-6 and TNFa levels in MSCs and in MSCs-MVs treated groups were significantly decreased when compared to DENPs toxicity group. In DENPs group there was a significant elevation in macrophages, whereas PMN and neutrophil levels were increased. On the other hand, MSCs and MSCs-MVs treated groups exhibited significant decrease in macrophages, PMN and neutrophil levels when compared with DENPs group (Table 2).

Table 1. Alveolar wall thickness $(\mu \mathrm{m})$, mean area percentage of elastic fibers and optical density of NF-kB

\begin{tabular}{|c|c|c|c|c|}
\hline Groups & $\begin{array}{l}\text { Control } \\
\text { group }\end{array}$ & $\begin{array}{l}\text { DENPs } \\
\text { group }\end{array}$ & $\begin{array}{l}\text { MSCs } \\
\text { group }\end{array}$ & $\begin{array}{l}\text { MSCs-MVs } \\
\text { group }\end{array}$ \\
\hline Alveolar wall thickness $(\mu \mathrm{m})$ & $2.61 \pm 1.51$ & $11.26 \pm 9.12^{*}$ & $5.32 \pm 1.70^{\mathrm{a} *}$ & $3.13 \pm 0.42^{a}$ \\
\hline Mean area percentage of elastic fibers & $9.94 \pm 0.83$ & $1.42 \pm .03^{*}$ & $6.29 \pm 0.10^{a_{*}}$ & $7.98 \pm 0.90^{a}$ \\
\hline Optical density of NF-kB & $0.1 \pm 0.01$ & $3.37 \pm 0.02$ & $0.19 \pm 0.03^{a^{*}}$ & $0.12 \pm 0.07^{a}$ \\
\hline
\end{tabular}

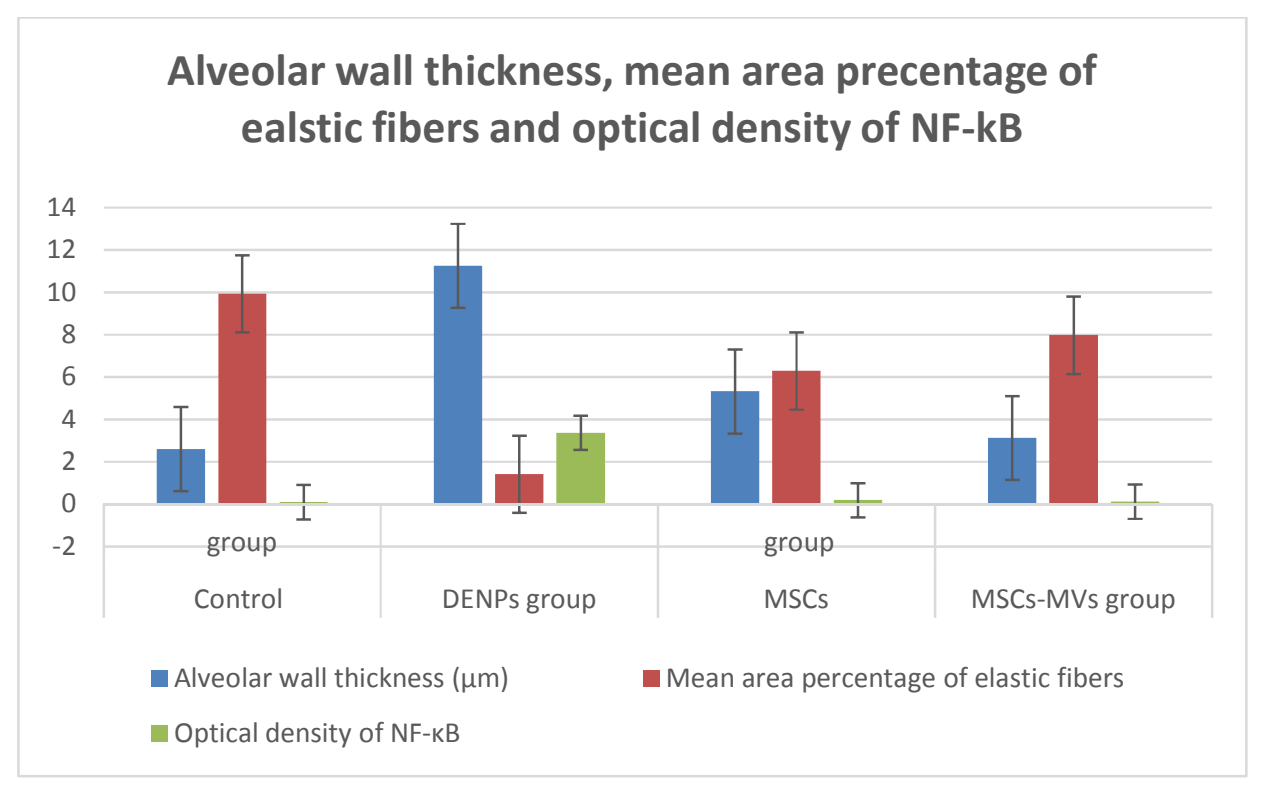

Table 2. Levels of TNF- $\alpha$, IL-6, inflammatory cells, total cell count and total protein in BALF

\begin{tabular}{|c|c|c|c|c|}
\hline Groups & Control group & DENPs group & MSCs group & MSCs-MVs group \\
\hline IL-6 (pg/ml) & $0.98 \pm 0.12$ & $3.92 \pm 0.34$ & $1.39 \pm 0.60 a^{a_{*}}$ & $1.03 \pm 0.15^{\mathrm{a}}$ \\
\hline TNF- $\alpha(p g / m l)$ & $25.89 \pm 6.59$ & $63.44 \pm 10.53^{\pi}$ & $29.34 \pm 0.20^{\mathrm{a}}$ & $28.78 \pm 0.90^{a}$ \\
\hline Macrophages & $0.98 \pm 0.12$ & $2.92 \pm 0.34$ & $1.21 \pm 0.15^{\mathrm{a}}$ & $1.00 \pm 0.91^{\mathrm{a}}$ \\
\hline PMNs & $25.89 \pm 6.59$ & $82.41 \pm 10.53^{\pi}$ & $29.34 \pm 0.20^{a}$ & $27.78 \pm 0.90^{a}$ \\
\hline Neutrophils & $40.31 \pm 1.94$ & $63.44 \pm 10.53^{\pi}$ & $49.32 \pm 2.14^{\mathrm{a}^{\mathrm{x}}}$ & $47.58 \pm 0.32^{\mathrm{a}^{\pi}}$ \\
\hline Total protein $(\mathrm{mg})$ & $57.41 \pm 1.46$ & $120.34 \pm 4.20^{*}$ & $61.33 \pm 8.70^{\mathrm{a}^{x}}$ & $59.08 \pm 0.81^{a}$ \\
\hline Albumin (mg) & $2.1 \pm 0.65$ & $4.9 \pm 2.73^{x}$ & $2.1 \pm 0.10^{a}$ & $2.0 \pm 0.11^{a}$ \\
\hline $\mathrm{LDH}$ & $2.01 \pm 1.49$ & $0.95 \pm 0.83^{\pi}$ & $1.7 \pm 0.50^{a}$ & $1.8 \pm 0.81^{a}$ \\
\hline
\end{tabular}


level of IL, TNF,Macophage,PMNs,Neutrophils, total protein ,albumin and LDH in BALF
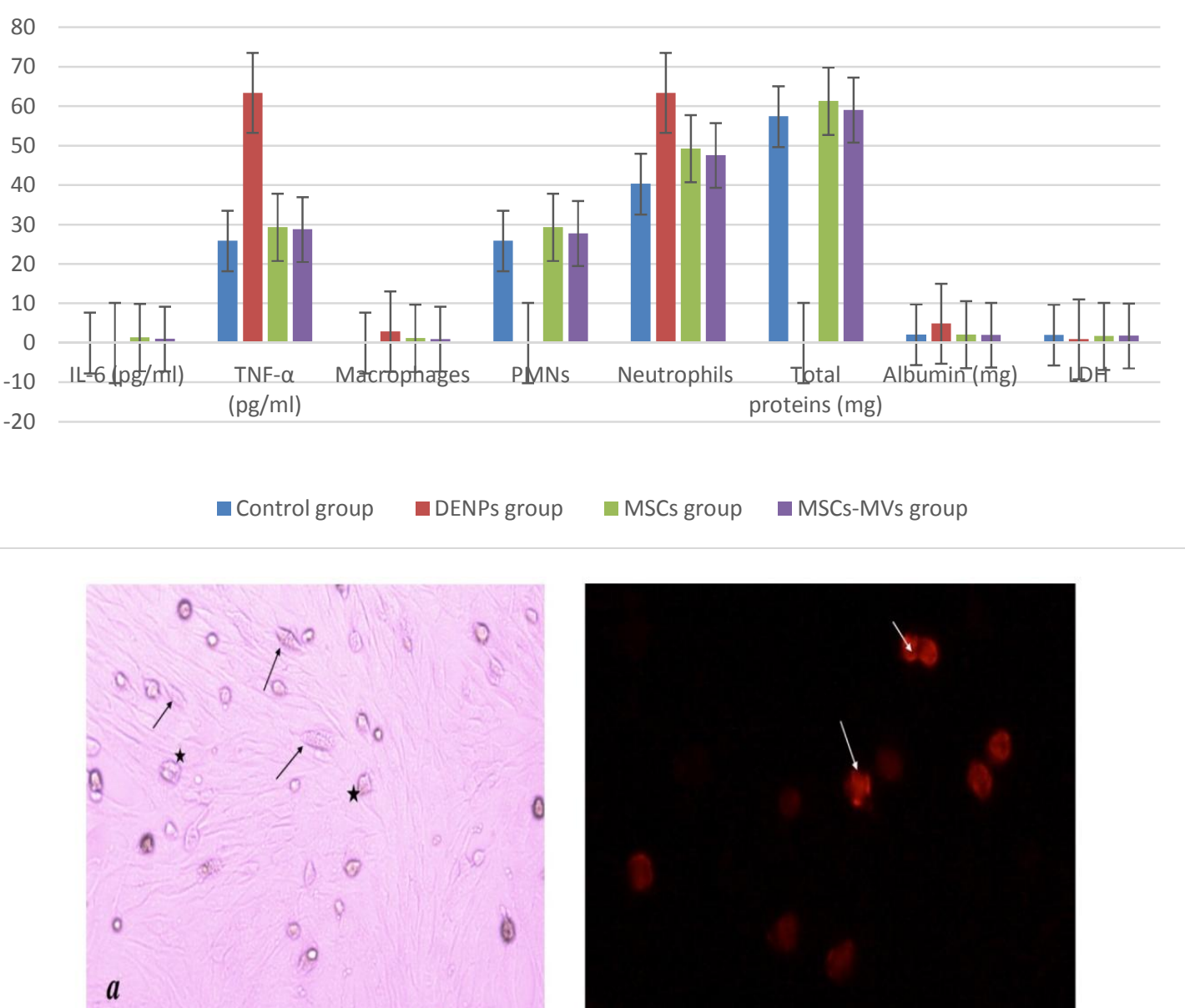

A.
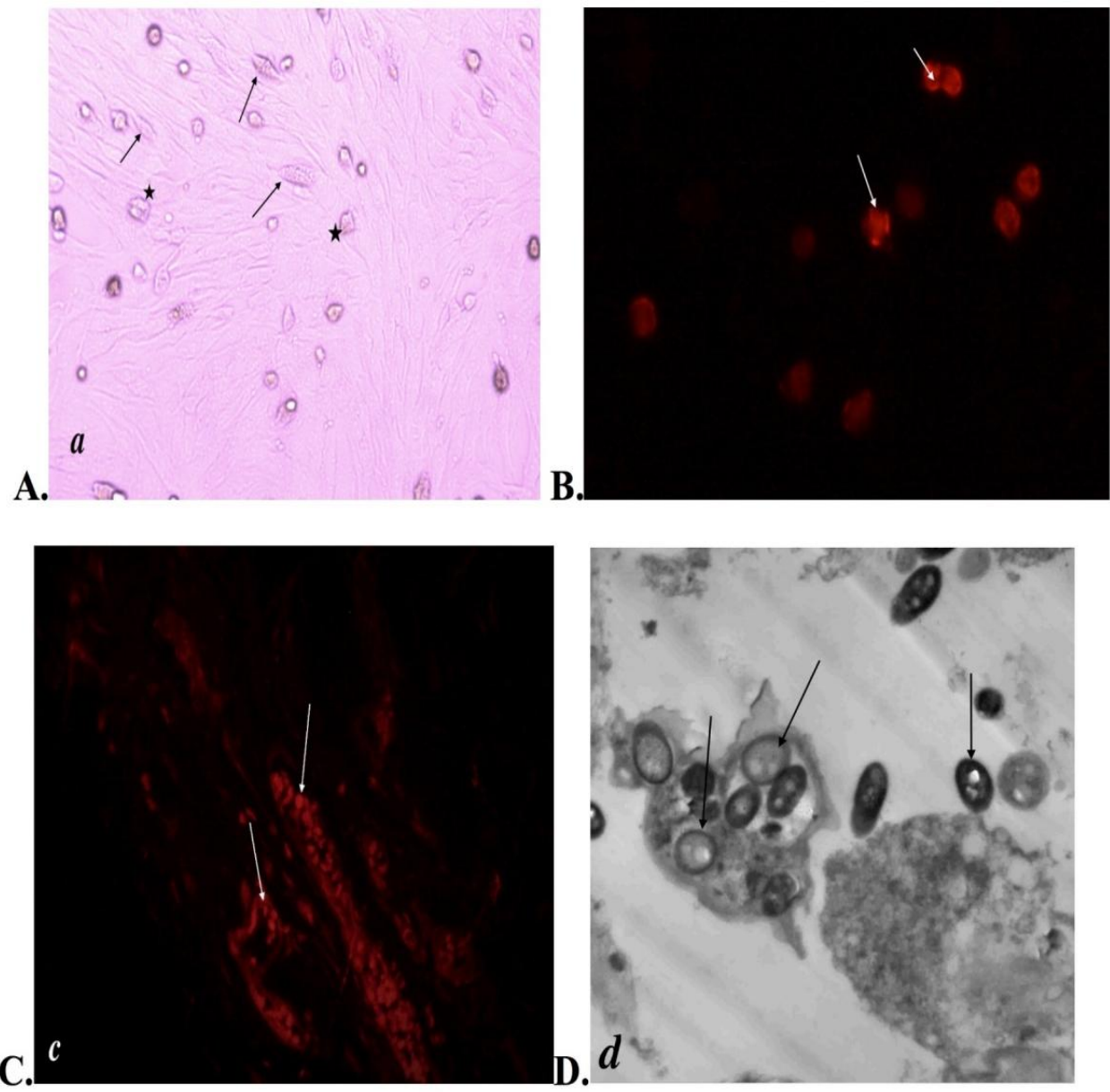
E.
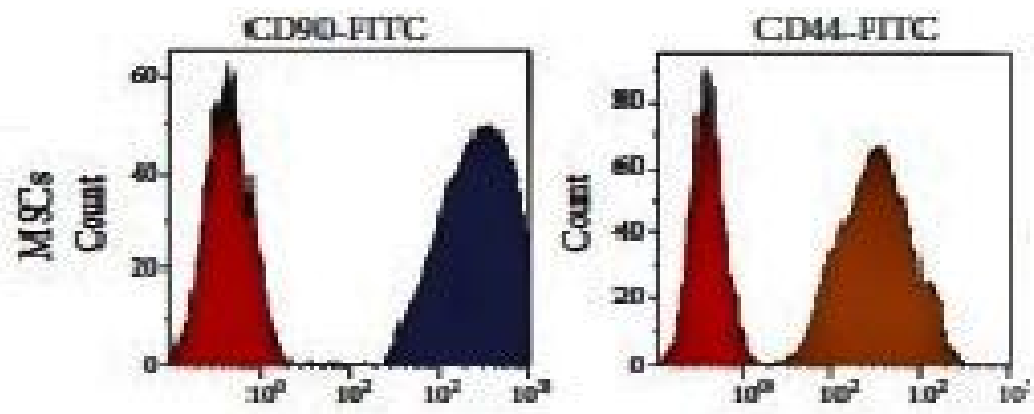

Fig. 1. (A) Inverted microscope micrograph of a culture of bone marrow-derived mesenchymal stem cells on day 14 of isolation and culture. The attached cells form colonies. These cells are spindle shaped $(\uparrow)$ with some polyhedral cells $\left(^{*}\right)$ in between the colonies (X1000). (B) A fluorescent microscope photograph showing MSCs labelled with PKH26 fluorescent dye in vitro (arrows) (A 1000); (C) A fluorescent microscope photograph showing MSCs labelled with PKH26 fluorescent dye in lung (arrows) (A 1000). (D) Electron micrograph of micro vesicles showing spheroid appearance (black arrows) in lung $(100 \mathrm{~nm})$. (E) flow cytometry which revealed that MSCs were have CD90+ and CD44

A)

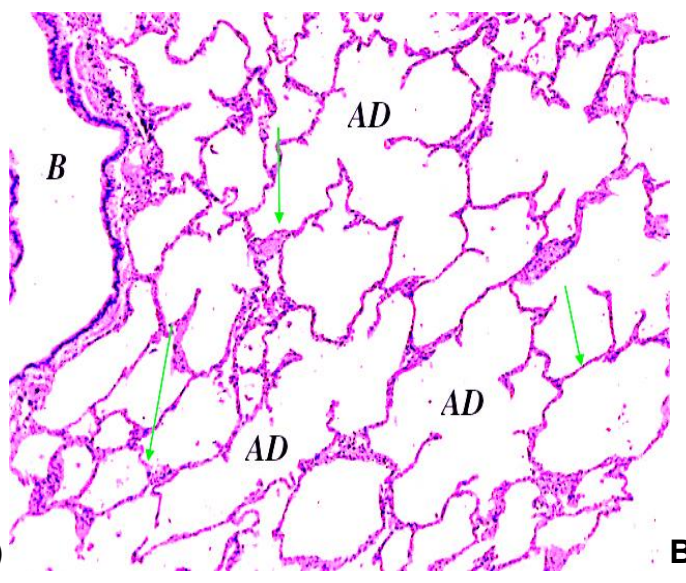

B)

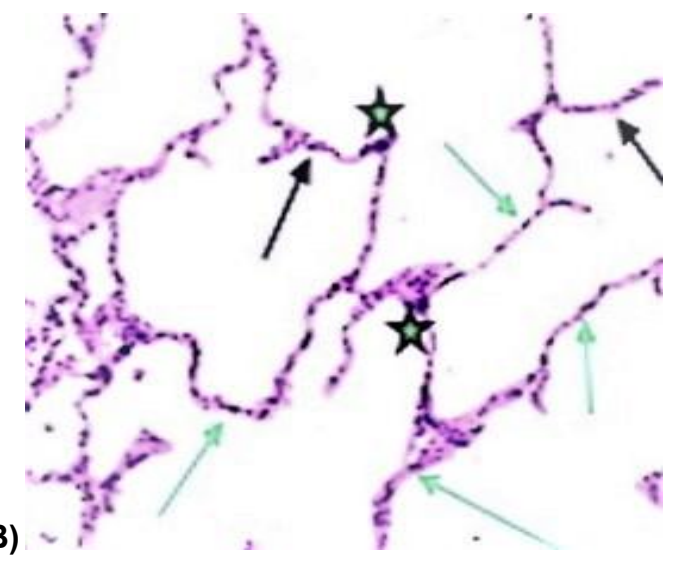

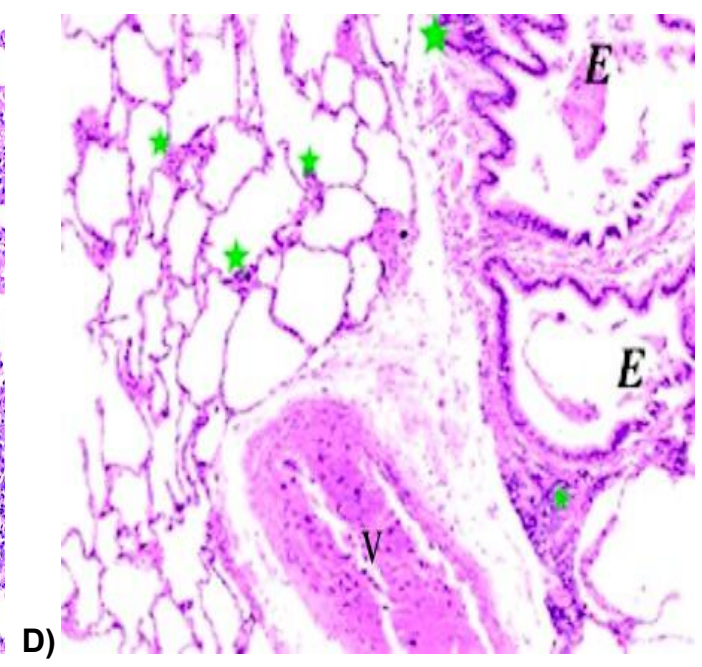



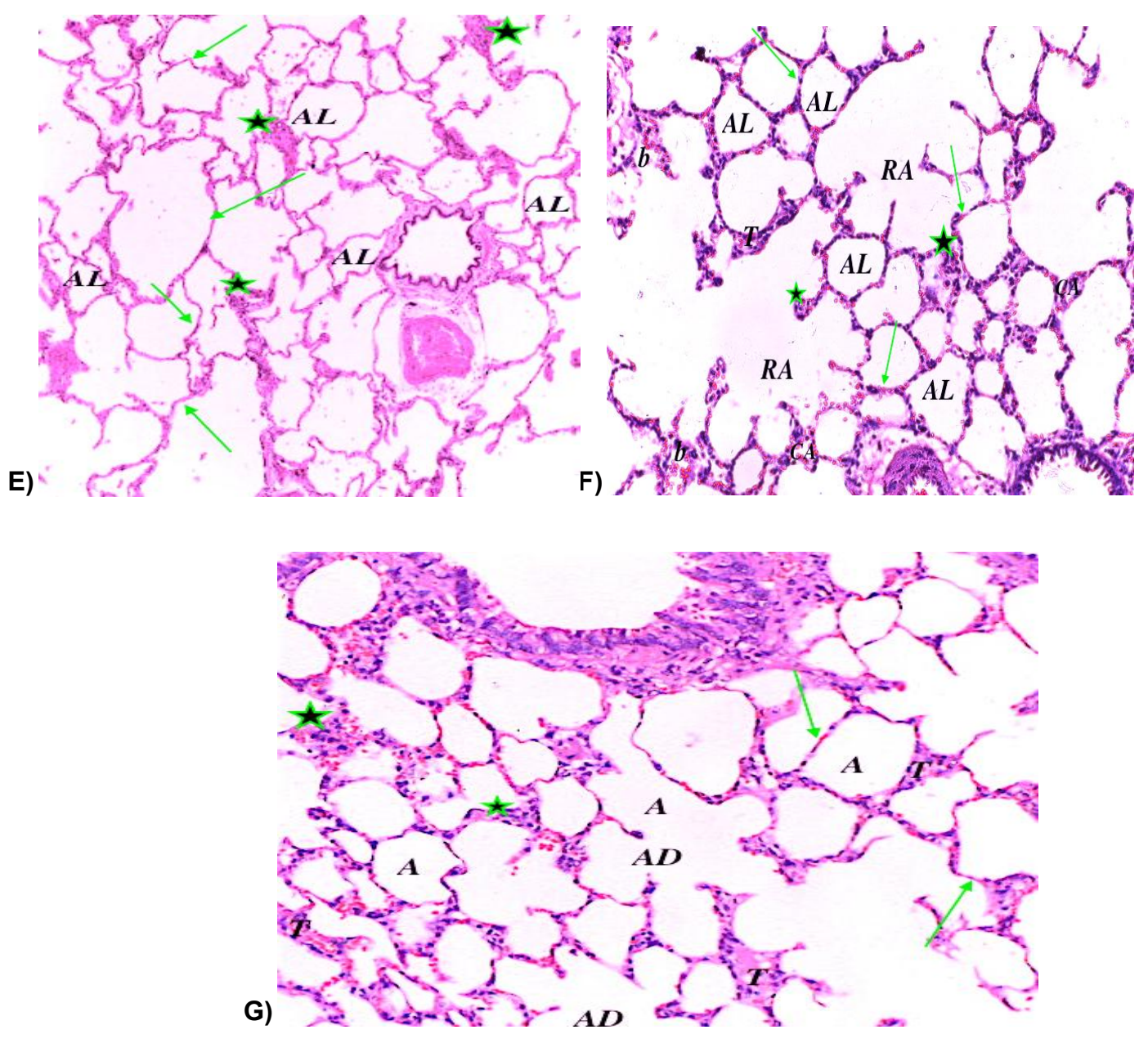

Fig 2. (A) A photomicrograph of a section in rat lung of group I (control group) showing alveoli (A), alveolar duct (AD), bronchiole (B) thin interalveolar septa (arrows) and a blood vessel (V) H\&E, 200. (B) A section in rat lung of group I (control group) showing pneumocyte type I (green arrows), pneumocyte type II (black arrows) and alveolar macrophages (star), H\&E, 650. (C) Lung tissue of group II (DENPs treated group) showed some collapsed alveoli (c) with thick interalveolar septa (T), cellular infiltration around bronchiole and alveoli (stars), extravasated red blood cells (b) H\&E, 200. (D) Group II (DENPs treated group) showed exfoliated epithelial cells in the lumen of bronchiole (f), cellular infiltration around bronchiole and alveoli (stars) and dilated congested blood vessel (v) H\&E, 200. (E) Group III (MSCs group) showed some alveoli normal (AL) with thin interalveolar septa (arrows) and few cellular infiltrations (stars) H\&E, 200. (F) A section of lung tissue of group III showed alveoli (AL) with thin interalveolar septa (arrows), some dilated ruptured alveoli (RA) and cellular infiltration (stars) and less extravasated RBCs (b), others collapsed alveoli (CA) with thick interalveolar septa (T) H\&E, 200. (G) Group IV (MSCs-EVs) showed many alveoli of variable size (A) with alveolar ducts (AD) and thin interalveolar septa (arrows) with few others showed thickened interalveolar septa (T) with few mononuclear cellular infiltration(stars) H\&E, 200

The total protein was increased in DENPs group. MSCs and MSCs-MVs treated groups showed significant decrease when compared to the DENPs group. Albumin concentration was elevated in DENPs toxicity group and significantly decreased in both MSCs and MSCsMVs treated groups. Whereas, the LDH level was increased in DENPs group and decreased in both MSCs and MSCs-MVs treated groups (Table 2). 


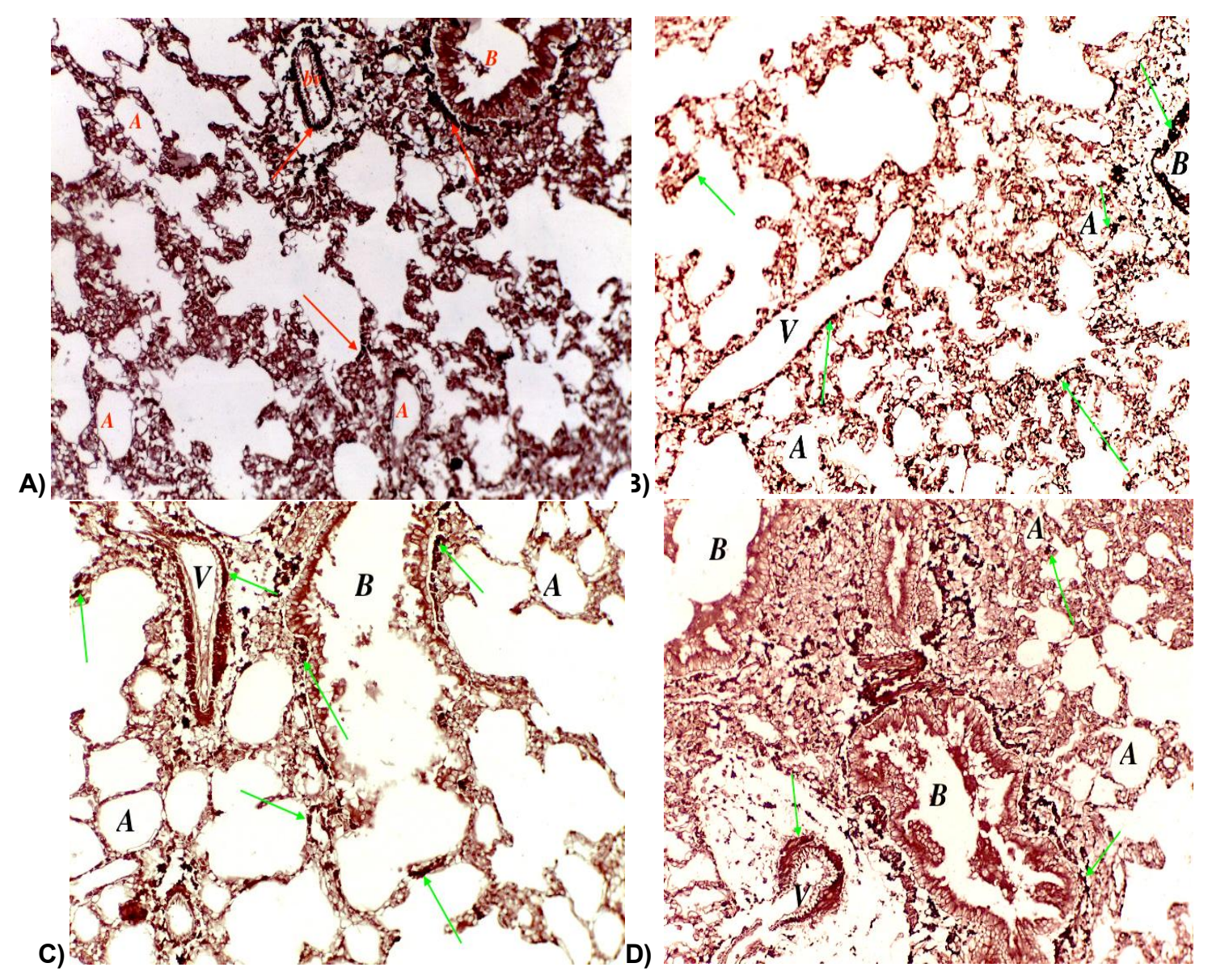

Fig 3. (A) A photomicrograph of Group I (control group) showing continuous reddish-brown elastic fibers (arrows) around the walls of the alveoli (A), bronchiole (B) and blood vessel (bv) (Orcein stain, X200). (B) Group II showing mild accumulation of reddish-brown elastic fibers (arrows) around the bronchiole (B), walls of the alveoli (A) and wall of dilated blood vessel (V) (Orcein stain, X200). (C) Group III (MSCs group) showing moderate accumulation of reddishbrown elastic fibers (arrows) around the bronchiole (B), wall of congested blood vessel (bv) and walls of the alveoli (A) (Orcein stain, X200). (D) Group IV (MSCs-MVs) showing marked amount of reddish-brown elastic fibers around the bronchiole passages $(B)$ and walls of the alveoli (A) (Orcein stain, X200)

A)

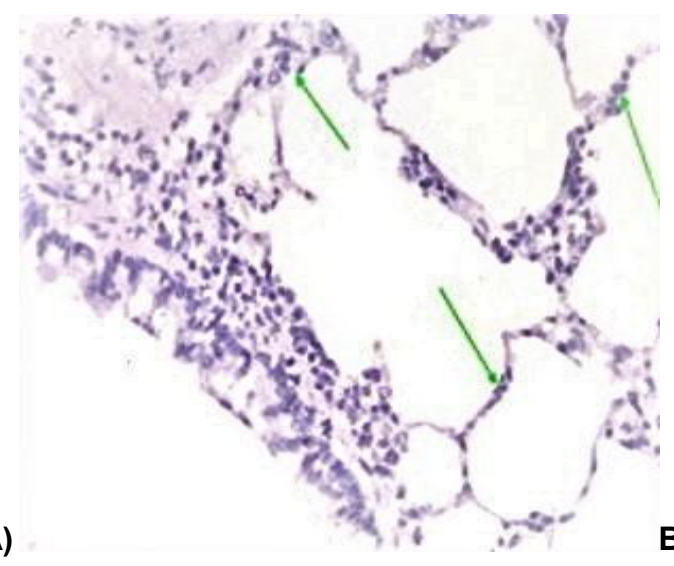

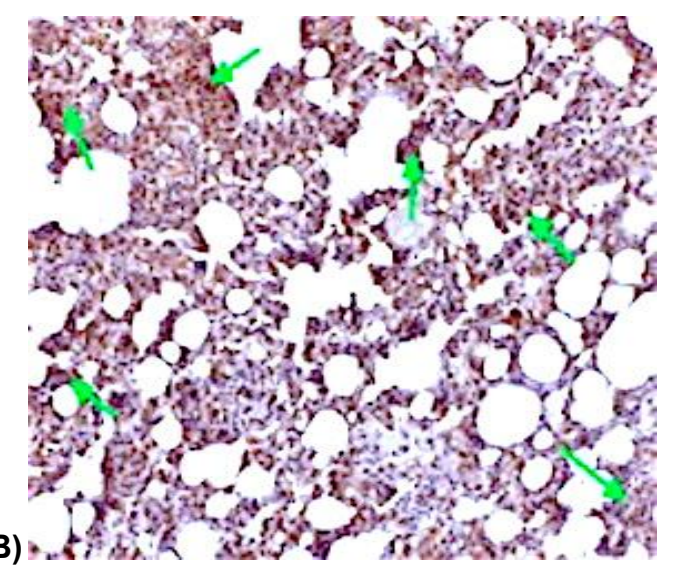



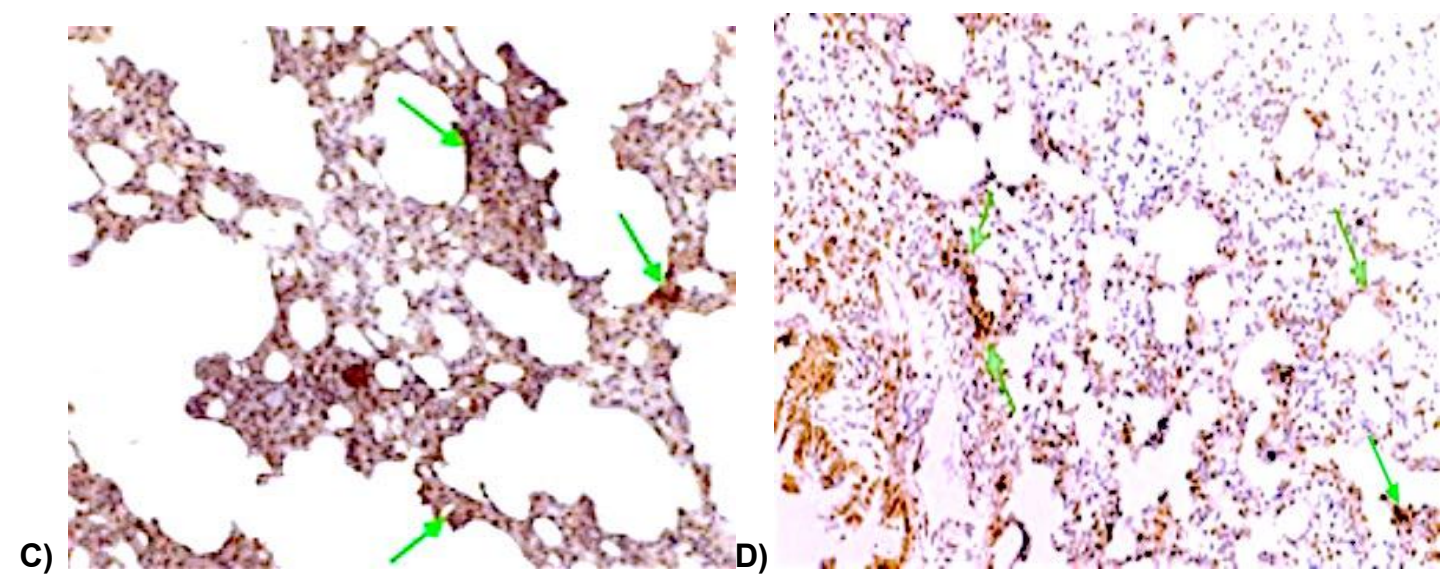

Fig 4. (A) Photomicrograph of lung section of Group I showed negative NF-KB immunoreactivity (arrow) within the cytoplasm of cells. (B) Group II (DENPs treated group) rat lung showing marked positive NF-KB immunoreactivity (arrows). (C) group III (MSCs group) showing moderate positive NF-KB immunoreactivity (arrows). D) Group IV (MSCs-MVs) showing mild positive NF-KB immunoreactivity (arrows). (Immunostaining for NF-KB X200)

\section{DISCUSSION}

Since 1990 it was realized that the adverse health effects of DENPs depend mainly on pulmonary inhalation with subsequent induction of oxidative stress, pro-inflammatory signaling molecules and genotoxicity. DENPs are translocated across the airway respiratory epithelium and enter the circulatory system, along with locally produced inflammatory signaling molecules and oxidizing molecules which initiate systemic inflammation, oxidative stress and systemic distribution of genotoxins [2]. These fact confirm our findings of elevated levels of inflammatory cytokines; IL-6 and TNF- $\alpha$ as well as inflammatory cellular infiltration of the lung tissue in DENPs exposed rat group. More recently, Durga et al. [27] stated that inflammatory cytokines, reactive oxygen species (ROS) and genotoxins induce endothelial cells transition into mesenchymal fibroblast-like cells with subsequent progression of chronic diseases to organ fibrosis and carcinogenesis. It was shown that endothelial protein pattern changes with modulation of the expressions of endothelial/ fibrotic markers and extracellular matrix proteins. These observations could explain findings of this study that revealed significant accumulation of elastic fibers around the bronchiole, walls of the alveoli, and wall of the congested blood vessel together with marked increase in the alveolar wall thickness in lung tissues of DENPs exposed rat group. These findings could also be attributed to activation of immune cells by reactive oxygen species (ROS) and reactive nitrogen species (RNS) which initiate pulmonary fibrosis as proved in the previous study conducted by Yetuk et al. [28]. One of the key inducers of inflammatory responses is NFK-B (26). Activation of NFK-B results from interactions between polyaromatic hydrocarbons found in DENPs with the intracellular Aryl-hydrocarbon receptors [29, 30]. Also, increase of nuclear factor kappa B by diesel exhaust particles in mouse epidermal cells through phosphatidylinositol 3-kinase/Akt signaling pathway [29]. Evidence of Lung injury in our study was shown by elevated albumin level in BALF. These findings coincided with previous studies [31,32].

As regards use of MSCs and MSCs-MVs, results of this study showed that both treated rat groups showed significant amelioration of the histological picture of lung tissue injury, significant decrease in inflammatory cytokines; IL-6 and TNF-a and significant decrease in albumin and increase in LDH levels in BALF. These observations could be attributed to the anti-inflammatory and immunomodulatory capacity of MSCs [5, 9]. Willis et al. [33] reported that MSCs-derived EVs; one type of extracellular vesicles significantly blunt inflammation, decrease fibrosis, and improve pulmonary functions in experimental bronchopulmonary dysplasia. MSCs- MV mechanism of action involves suppression of the pro-inflammatory state and switch to an anti-inflammatory state via modulation of macrophage functions in lung tissues. These facts could explain our findings of decreased markers of lung injury which treated by MSCs-MS; albumin as well as decreased inflammatory cytokines, inflammatory cells 
infiltration of the lung and increase LDH with subsequent increase in elastic fibers and decrease in alveolar wall thickness.

MSC-MVs have many therapeutic effects in different diseases, as renal injury, brain injury, heart injury and lung injury [34]. The therapeutic ability of MSC-MVs has been studied in different disease models, showing a similar or even superior effect to MSCs themselves [35-36] which has showed in our result.

Recent studies on MSC-MVs in preclinical experimental models of inflammatory lung diseases have shown that they could be safely and easily used in lung disease therapies [37].

\section{CONCLUSION}

In Conclusion, MSCs-MVs and MSCs showed significant protective effects against DENPs damaging effects on the lung tissues via their regenerative capacity and anti-inflammatory effects.

\section{ETHICAL APROVAL}

Institutional animal ethical committee reviewed \& approved our study according to the standard protocols of the Institutional Animal Care Committee.

\section{COMPETING INTERESTS}

Authors have declared that no competing interests exist.

\section{REFERENCES}

1. Khalek IA, Bougher TL, Merritt PM, Zielinska B. Regulated and unregulated emissions from highway heavy-duty diesel engines complying with U.S. Environmental Protection Agency 2007 emissions standards. J Air Waste Manag Assoc. 2011;61(4):427-42.

[PubMed] [Ref list] PMID: 21516938

2. Steiner S, Bisig C, Petri-Fink A, RothenRutishauser B. Diesel exhaust: Current knowledge of adverse effects and underlying cellular mechanisms. Arch Toxicol. 2016;90(7):1541-1553

DOI: 10.1007/s00204-016-1736-5

[PMID: 27165416]

3. Abderrahim Nemmar, Priya Yuvaraju, Sumaya Beegam, Mohamed A. Fahim, Badreldin $H$. Ali. Cerium oxide nanoparticles in lung acutely induce oxidative stress, inflammation, and DNA damage in various organs of mice. Oxid Med Cell Longev. 2017;9639035.

DOI: 10.1155/2017/9639035 [PMCID: PMC5368370. PMID: 28392888]

4. Samantha J. Snow, John McGee, Desinia B. Miller, Virginia Bass, Mette C. Schladweiler, Ronald F. Thomas, Todd Krantz, Charly King, Allen D. Ledbetter, Judy Richards, Jason P. Weinstein, Teri Conner, Robert Willis, William P. Linak, David Nash, Charles E. Wood, Susan A. Elmore, James P. Morrison, Crystal L. Johnson, Matthew lan Gilmour, Urmila P. Kodavanti. Inhaled diesel emissions generated with cerium oxide nanoparticle fuel additive induce adverse pulmonary and systemic effects. Toxicol Sci. 2014; 142(2):403-417.

DOI: $10.1093 /$ toxsci/kfu187

5. Abdelmawgoud $\mathrm{H}$, Saleh A. Antiinflammatory and antioxidant effects of mesenchymal and hematopoietic stem cells in a rheumatoid arthritis rat model. Adv Clin Exp Med. 2018;27(7):873-880.

DOI: $10.17219 /$ acem/73720

6. Shi $H$, Liang $M$, Chen $W$, Sun $X$, Wang $X$, Li C, Yang $Y$, Yang Z, Zeng W. Human induced pluripotent stem cell-derived mesenchymal stem cells alleviate atherosclerosis by modulating inflammatory responses. Mol Med Rep. 2018;17(1): 1461-1468.

DOI: $10.3892 / \mathrm{mmr} .2017 .8075$

7. Mao F, Tu Q, Wang L, Chu F, Li X, Li HS, $\mathrm{Xu} W$. Mesenchymal stem cells and their therapeutic applications in inflammatory bowel disease. Oncotarget. 2017;8(23): 38008-38021.

DOI: 10.18632/oncotarget.16682

8. Shin TH, Kim HS, Choi SW, Kang KS. Mesenchymal stem cell therapy for inflammatory skin diseases: Clinical Potential and Mode of Action. Int J Mol Sci. 2017;18(2).

DOI: $10.3390 / \mathrm{ijms} 18020244$

9. Sun L, Akiyama K, Zhang H, Yamaza $T$, Hou Y, Zhao S, Xu T, Le A, Shi S. Mesenchymal stem cell transplantation reverses multiorgan dysfunction in systemic lupus erythematosus mice and humans. Stem Cells. 2009;27:1421-1432. DOI: $10.1002 /$ stem.68

10. Robert Y. L. Tsai. Balancing self-renewal against genome preservation in stem cells: How to have the cake and eat it too? Cell Mol Life Sci. 2016;73(9):1803-1823. 
DOI: 10.1007/s00018-016-2152-y

[PMCID: PMC5040593]

11. Nagaria P, Robert C, Rassool FV. DNA double-strand break response in stem cells: Mechanisms to maintain genomic integrity. Biochim Biophys Acta. 2013; 1830(2):2345-2353.

DOI: 10.1016/j.bbagen.2012.09.001

12. Mandal PK, Blanpain C, Rossi DJ. DNA damage response in adult stem cells: Pathways and consequences. Nat Rev Mol Cell Biol. 2011;12(3):198-202.

DOI: $10.1038 / \mathrm{nrm} 3060$

13. Kowalska M, Wegierek-Ciuk A, Brzoska K, Wojewodzka M, Meczynska-Wielgosz S, Gromadzka-Ostrowska J, Mruk R, Øvrevik J, Kruszewski M, Lankoff A. Genotoxic potential of diesel exhaust particles from the combustion of first- and secondgeneration biodiesel fuels-The Fuel Health project. Environ Sci Pollut Res Int. 2017; 24(31):24223-24234.

DOI: 10.1007/s11356-017-9995-0

14. Fujita $Y$, Yoshioka $Y$, Ochiya T. Extracellular vesicle transfer of cancer pathogenic components. Cancer Sci. 2016; 107:385-390.

[Cross Ref] [PubMed]

15. Witwer KW, Buzas El, Bemis LT, Bora A, Lasser C, Lotvall J, Nolte-'t Hoen EN, Piper MG, Sivaraman S, Skog J, et al. Standardization of sample collection, isolation and analysis methods inextracellular vesicle research. J. Extracell. Vesicles. 2013;2:20360.

[CrossRef] [PubMed]

16. Yanez-Mo $M$, Siljander $P R$, Andreu $Z$, Zavec AB, Borras FE, Buzas El, Buzas K, Casal E, Cappello F, Carvalho J, et al. Biological properties of extracellular vesicles and their physiological functions. J. Extracell. Vesicles. 2015;4:27066.

17. Durga $M$, Nathiya $S$, Devasena $T$. Protective role of fenugreek leaf extract and Quercetin against petrol exhaust nanoparticle induced lipid peroxidation and oxidative stress in rat erythrocytes in vitro. Asian J Pharm Clin Res. 2015;8(1):237241.

Available:http://citeseerx.ist.psu.edu/viewd oc/download?doi=10.1.1.852.8353\&rep=re p1\&type $=p d f$

18. Baghaei K, Hashemi SM, Tokhanbigli S, Asadi Rad A, Assadzadeh-Aghdaei $\mathrm{H}$, Sharifian A, Zali MR. Isolation, differentiation, and characterization of mesenchymal stem cells from human bone marrow. Gastroenterol Hepatol Bed Bench. 2017; 10(3):208-213.

[PMCID: PMC5660271]

19. Gorgun C, Reverberi D, Rotta G, Villa F, Quarto R, Tasso R. Isolation and flow cytometry characterization of extracellularvesicle subpopulations derived from human mesenchymal stromal cells. Curr Protoc Stem Cell Biol. 2019;48:e76.

[PMID: 30624011]

DOI: $10.1002 / \mathrm{cpsc} .76$

20. Nassar W, El-Ansary M, Sabry D, et al. Umbilical cord mesenchymal stem cells derived extracellular vesicles can safely ameliorate the progression of chronic kidney diseases. Biomater Res 2016;20: 21.

[PMCID: PMC4974791]

DOI: 10.1186/s40824-016-0068-0

21. Faruk EM, El-desoky RE, Al-Shazly AM, Taha NM. Does exosomes derived bone marrow mesenchymal stem cells restore ovarian function by promoting stem cell survival on experimentally induced polycystic ovary in adult female albino rats? (Histological and immunohistochemical study). Stem Cell Res Ther. 2018;8:442.

DOI: 10.4172/2157-7633.1000442

22. Alturkistani HA, Tashkandi FM, Mohammedsaleh ZM. Histological stains: a literature review and case study. Glob $\mathrm{J}$ Health Sci. 2016;8(3):72-79.

DOI: $10.5539 / g j h s . v 8 n 3 p 72$

23. Bancroft JD, Layton C. The hematoxylin and eosin. In: Suvarna SK, Layton C, Bancroft JD, editors. Theory practice of histological techniques. $7^{\text {th }}$ ed. Ch. 10 and 11. Philadelphia: Churchill Livingstone of El Sevier. 2013;179-220.

Available:http://dx.doi.org/10.1016/b978-07020-4226-3.00010-x

24. Collins AM, Rylance J, Wootton DG, Wright AD, Wright AK, Fullerton DG, Gordon SB. Bronchoalveolar lavage (BAL) for research. Obtaining adequate sample yield. J Vis Exp. 2014;85.

DOI: $10.3791 / 4345$

25. Oyabu T, Myojo T, Lee BW, Okada T, Izumi H, Yoshiura Y, Tomonaga T, Li YS, Kawai K, Shimada M, Kubo M, Yamamoto K, Kawaguchi K, Sasaki T, Morimoto Y. Biopersistence of $\mathrm{NiO}$ and $\mathrm{TiO}_{2}$ nanoparticles following intratracheal instillation and inhalation. Int J Mol Sci. 2017;18(12): 2757. 
DOI: 10.3390/ijms18122757

26. Bradford M. A rapid and sensitive method for the quantitation of microgram quatities of protein utilizing the principle of proteindye binding. Analytical Biochemistry. 1976; 72(1-2):248-254.

27. Durga M, Nathiya S, Rajasekar A, Devasena T. Effects of ultrafine petrol exhaust particles on cytotoxicity, oxidative stress generation, DNA damage and inflammation in human A549 lung cells and murine RAW 264.7 macrophages. Environ Toxicol Pharmacol. 2014;38(2):518-30.

28. Yetuk G, Pandir D, Bas H. Protective role of catechin and quercetin in sodium benzoate-induced lipid peroxidation and the antioxidant system in human erythrocytes in vitro. Scientific World Journal. 2014;874824.

29. Jennifer A. Bartlett, Matthew E. Albertolle, Christine Wohlford-Lenane, Alejandro A. Pezzulo, Joseph Zabner, Richard K. Niles, Susan J. Fisher, Paul B. McCray, Jr., Katherine E. Williams protein composition of bronchoalveolar lavage fluid and airway surface liquid from newborn pigs. Am J Physiol Lung Cell Mol Physiol. 2013; 305(3):L256-L266.

DOI: 10.1152/ajplung.00056.2013

30. Samantha JS, John M, Desinia B, Virginia $B$, Mette $C$, et al. Inhaled diesel emissions generated with cerium oxide nanoparticle fuel additive induce adverse pulmonary and systemic effects. Toxicological Sciences. 2014;142:2.

31. Pérez L, Muñoz-Durango N, Riedel CA, Echeverría C, Kalergis AM, CabelloVerrugio C, Simon F. Endothelial-tomesenchymal transition: Cytokinemediated pathways that determine endothelial fibrosis under inflammatory conditions. Cytokine Growth Factor Rev. 2017;33:41-54.

DOI: 10.1016/j.cytogfr.2016.09.002
32. Ma JY, Mercer RR, Barger M, SchweglerBerry D, Scabilloni J, Ma JK, Castranova $\mathrm{V}$. Induction of pulmonary fibrosis by cerium oxide nanoparticles. Toxicol Appl Pharmacol. 2012;262(3):255-64.

DOI: 10.1016/j.taap.2012.05.005

33. Willis GR, Fernandez-Gonzalez A, Anastas J, Vitali SH, Liu X, Ericsson M, Kwong A, Mitsialis SA, Kourembanas S. Mesenchymal stromal cell ameliorates experimental bronchopulmonary dysplasia and restore lung function through macrophage immunomodulation. Am J Respir Crit Care Med. 2018;197(1):104116.

DOI: $10.1164 / \mathrm{rccm} .201705-09250 \mathrm{C}$

34. Phinney DG, Pittenger MF. Concise review: MSC-derived exosomes for cellfree therapy. Stem Cells. 2017;35:851858.

[CrossRef] [PubMed]

35. Bian S, Zhang L, Duan L, Wang X, Min Y, $\mathrm{Yu} \mathrm{H}$. Extracellular vesicles derived from human bone marrow mesenchymal stem cells promote angiogenesis in a rat myocardial infarction model. J. Mol. Med. (Berl.). 2014;92:387-397.

[CrossRef] [PubMed]

36. Faruk EM, El Mansy A, Alasmari WAM, Elshazly AME. The possible protective role of quercetin on induced cardiac oxidative DNA damage by repeated exposure to diesel exhaust nanoparticles in rats (a histological and immunohistochemical study). J Histol Histopathol. 2018;5(2).

DOI: $10.7243 / 2055-091 X-5-2$

37. Rezaie Z, Ardeshirylajimi A, Ashkezari MD, Seifati SM. Antitumoral potential of microvesicles extracted from human adiposederived mesenchymal stem cells on human breast cancer cells. J Can Res Ther. 2019;2:234-238.

Available:http://www.cancerjournal.net/pre printarticle. asp? $\mathrm{id}=\mathbf{2 5 1 3 9 6}$

(c) 2019 Salam et al.; This is an Open Access article distributed under the terms of the Creative Commons Attribution License (http://creativecommons.org/licenses/by/4.0), which permits unrestricted use, distribution, and reproduction in any medium, provided the original work is properly cited.

Peer-review history:

The peer review history for this paper can be accessed here: http://www. sdiarticle3.com/review-history/49401 